\title{
Monitoring of Reinforced Concrete for Decision Support in Maintenance Management Systems
}

\author{
Pedro Romano ${ }^{1,2}$, João Castro Gomes², and Paulo Brito ${ }^{1}$ \\ ${ }^{1}$ VALORIZA, Research Centre for Endogenous Resource Valorization, Polytechnic Institute of \\ Portalegre, 7300-511 Portalegre, Portugal \\ ${ }^{2}$ Centre of Materials and Building Technologies (C-MADE/UBI), Department of Civil Engineering \\ and Architecture, University of Beira Interior (UBI), 6201-001 Covilhã, Portugal
}

\section{Abstract}

The goal of this study is to collect and validate relevant information on the degradation of reinforced concrete exposed to aggressive environments, such as chlorides or sulfates, for later incorporation in maintenance management systems compatible with the BIM methodology (Building Information Modeling).

To achieve this, two simultaneous monitoring systems were used, one that allows measuring the ionic resistivity of the concrete and another that measures the corrosion potential and polarization resistance of the reinforcement. With the first monitoring system, it is intended to monitor the changes occurring in the concrete at the level of its ionic conductivity during the contamination process. The second system allows, at a later stage of the concrete degradation process, to detect signs of corrosion of the reinforcement inserted therein. Both systems provide readings at $10 \mathrm{~mm}$ and $30 \mathrm{~mm}$ depth measured from the face exposed to the action of the degradation agents.

The results obtained for chloride contamination show that the ionic resistivity of the concrete tends to decrease with the progression of the chlorides in depth, leading at a later stage to the corrosion of the reinforcement, which can be detected by the reduction of corrosion potential. Also, the polarization resistance of the reinforcement has been reduced when corrosion phenomena begin to develop in the reinforcement. The results related to the sulfate attack suggest a mechanism that leads to the formation of a barrier that prevents the progression of the attack in depth. The consequence of this phenomenon is a reduction of the ionic mobility of the concrete, leading to the increase of resistivity. This mechanism associated with the absence of mechanical actions that force the progression of sulfates in depth inhibits the development of corrosion processes of the reinforcement.

\section{Introduction}

Reinforced concrete has been the most used structural material in the construction of buildings and infrastructures over the last decades. Its durability depends on several factors such as its design, execution and maintenance. Despite the high expectations regarding its durability, reality shows that many structures show signs of premature 
degradation. This early degradation is an economic and social problem with strong environmental implications, in particular due to the potential increase of waste generated by the need to carry out unplanned rehabilitation works or, in extreme cases, the demolition of buildings [1]. One way to limit the consequences of early degradation is to use maintenance management systems to monitor structures over time. With the introduction of the BIM methodology, which allows the management of information throughout the life cycle of the constructions from the project to the demolition phase, new opportunities for the development of maintenance management tools are emerging. These new tools will allow to operationalize the exchange of information between the different actors in the maintenance process, increasing the effectiveness of these systems [2].

The management systems for the maintenance of reinforced concrete structures are intended to assurance the conditions of structural safety, safety of use and durability. To achieve these objectives maintenance management systems, lack objective information to justify maintenance decisions that will be implemented over the life of the structure. In the specific case of the durability of reinforced concrete structures, whose degradation processes are generally slow but involve high rehabilitation costs, appropriate indicators must be used to detect early and accompany these degradation phenomena [3].

The use of electrochemical parameters, such as ionic resistivity of the concrete or polarization resistance and the potential of the reinforcement, has been proposed by several authors to allow the monitoring of changes in the behavior of concrete and steel [4], [5]. These parameters provide relevant information about the change in behavior patterns of reinforced concrete, which can be used to determine the need to carry out regular or preventive maintenance tasks appropriate to the situation.

Concrete is a porous material so it is subject to the effects of degradation phenomena promoted by external agents, such as chlorides and sulfates. In the specific case of reinforced concrete, the main consequence of concrete degradation is the corrosion of the reinforcement. This phenomenon involves the loss of section and the increase of the volume due to the products of the corrosion, creating internal stresses in the concrete that lead to their cracking, and consequently to the acceleration of the degradation process [6].

In this work the laboratory results of the monitoring of reinforced concrete elements exposed to the action of chlorides and to the attack by sulfates are analyzed and compared. It is intended to show how the degradation process of reinforced concrete develops over time. 


\section{Experimental Phase}

The tests were developed in the laboratory using concrete samples with a volume of $400 \times 300 \times 150 \mathrm{~mm} 3$, reinforced with a mesh composed of three $10 \mathrm{~mm}$ diameter steel rods in each direction, as shown in Fig. 1. The concrete used was a C30/37, with the constitution indicated in the Table 1. The steel used was A400, with a $40 \mathrm{~mm}$ coating layer. In the upper face of the specimens was placed a box composed of acrylic plates for placement of the contamination solutions.

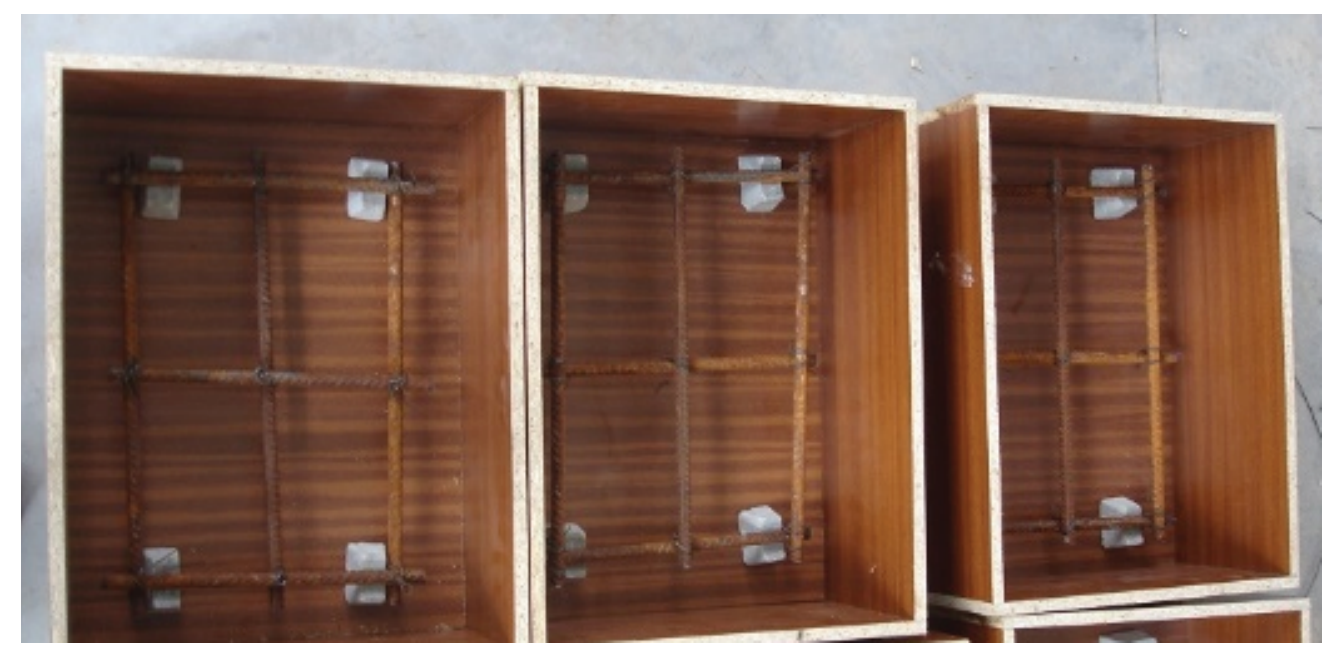

Figure 1: Preparation of samples for concreting.

TABLE 1: Concrete mix.

\begin{tabular}{cc}
\hline Concrete mix & Admixture $(\mathrm{kg} / \mathrm{m3})$ \\
\hline Sand $(0-2 \mathrm{~mm})$ & 302 \\
\hline Coarse sand $(0-4 \mathrm{~mm})$ & 506 \\
\hline gravel 1 & 1016 \\
\hline Cement & 340 \\
\hline Water & 170 \\
\hline
\end{tabular}

For monitoring, two types of electrochemical parameters measurement systems were used, one to measure the ionic resistivity of concrete and the other to identify signs of corrosion of the reinforcement by measuring corrosion potential and resistance of polarization.

The ionic resistivity of a material allows us to understand the degree of ionic contamination, which varies as a function of the mobility and the ion concentration. This parameter is influenced by the sizes and the load of the ions, temperature, humidity inside the pores and degree of external contamination. The Table 2 shows the relationship between the resistivity and the risk of corrosion of the reinforcement.

The corrosion rate, which measures the kinetics of the corrosive process, is used because it allows signaling the development of a corrosive process. This parameter is 
TABLE 2: Relation between the ionic resistivity of the concrete and the risk of corrosion of the reinforcement [7].

\begin{tabular}{cc}
\hline Resistivity (kOhm.cm) & Corrosion risk \\
\hline $\mathrm{R}>20$ & Negligible \\
\hline $20>\mathrm{R}>10$ & Low \\
\hline $10>\mathrm{R}>5$ & High \\
\hline $\mathrm{R}<5$ & Very high \\
\hline
\end{tabular}

obtained by the perturbation induced by the imposition of a continuous flow of electric current. The Table 3 shows the relationship between this parameter and the risk of corrosion of the reinforcement.

TABLE 3: Relation between corrosion potential and corrosion risk of reinforcement [8].

\begin{tabular}{cc}
\hline Potential of corrosion $(\mathbf{m V})$ & Corrosion risk \\
\hline $\mathrm{E}_{\text {corr }}>-200$ & Low $(10 \%$ risk of corrosion $)$ \\
\hline$-200>\mathrm{E}_{\text {corr }}>-350$ & Intermediate corrosion risk \\
\hline $\mathrm{E}_{\text {corr }}<-350$ & High $(90 \%$ risk of corrosion $)$ \\
\hline $\mathrm{E}_{\text {corr }}<-500$ & Severe corrosion \\
\hline
\end{tabular}

The polarization resistance is based on the determination of the slope of the polarization curve, between the Electric Potential $(E)$ of the reinforcement and the Polarization Intensity $\left(I_{E}\right)$, according to the following expression:

$$
R_{p o l}=\lim _{E \rightarrow E_{\text {corr }}} \frac{E-E_{\text {corr }}}{I_{E}}=\frac{\beta_{a} \beta_{c}}{2.3 A i_{\text {corr }}\left(\beta_{a}+\beta_{c}\right)}
$$

The Fig. 2 shows the monitoring systems used for the ionic resistivity of the concrete and for corrosion potential and linear polarization resistance of the steel.

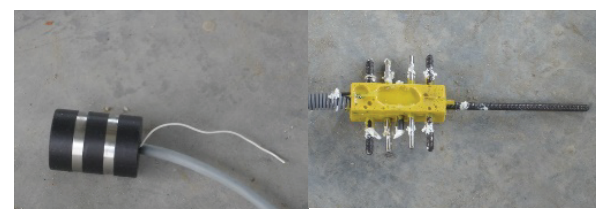

Figure 2: Monitoring systems used - ionic resistivity of the concrete (left) and corrosion potential and linear polarization resistance of the steel (right).

\subsection{Chloride tests}

For the contamination of the concrete samples a solution with $3 \%$ of sodium chloride was used. The evolution of chloride penetration was controlled by collecting samples of concrete powder at various depths throughout the test. After removal the concrete powder was analyzed by X-ray fluorescence. In Fig. 3 the test samples that served as the basis for these rests can be observed. 


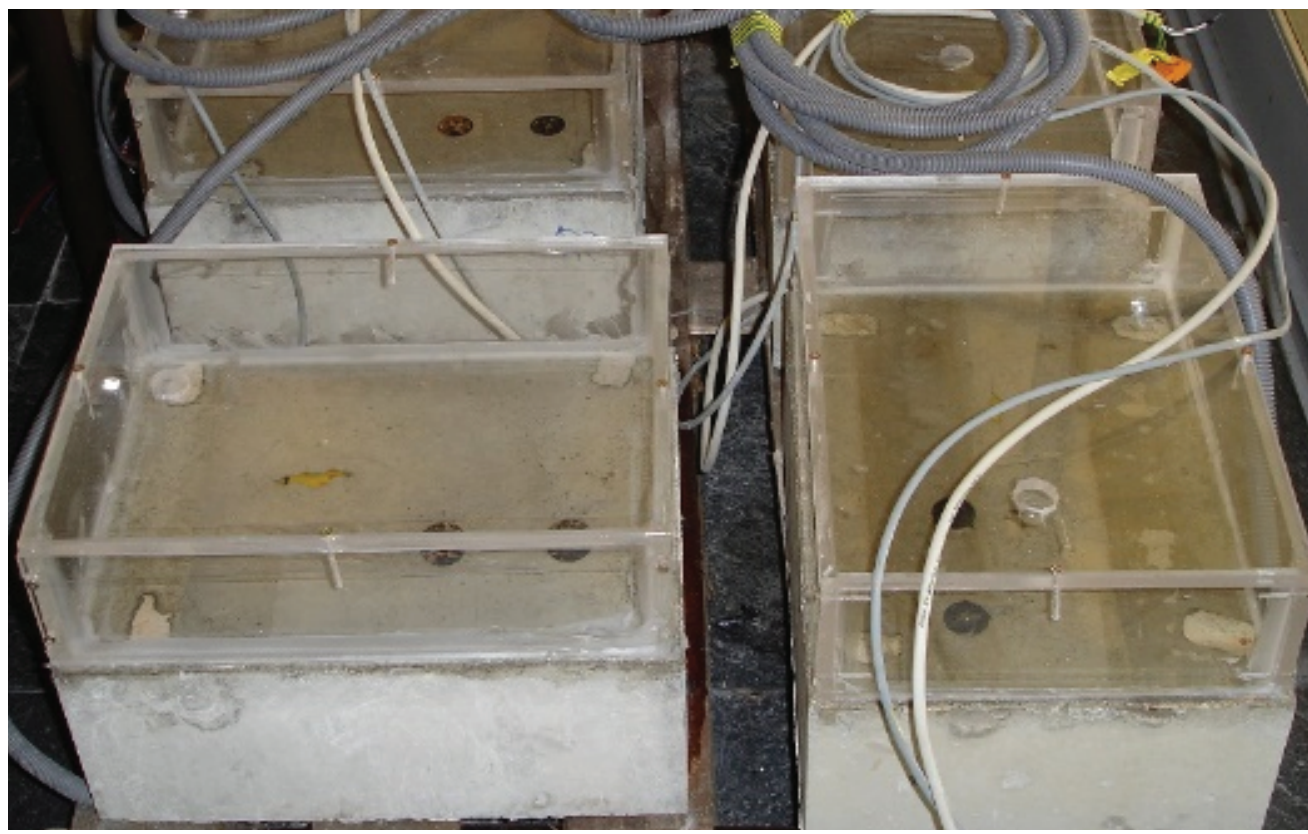

Figure 3: Concrete samples subject to a $3 \%$ solution of sodium chloride.

\subsection{Sulfate tests}

In these tests a solution composed of $2.5 \%$ of magnesium sulfate and $2.5 \%$ of sodium sulfate was used, as specified in ASTM C 1012-4 [9]. Control of the deep sulfate attack was performed by extracting concrete powder at various depths. The powder obtained was analyzed by fluorescence of X-rays, as in chlorides. In Fig. 4, the samples exposed to the action of the sulfates are presented.

\section{Results and Discussion}

The test samples were exposed to the action of chlorides and sulfates. Fig. 5 and Fig. 6 show the in-depth and over time evolution of the contamination produced in the concrete. The chlorides graph shows the penetration of the chlorides in the concrete during the test. In the graph relative to the sulfates it is observed that there is an increase of the concentration of these in the superficial layer throughout the process, which effect is not reflected in depth.

In Fig. 7 the evolution of the ionic resistivity of the concrete over time can be observed for the chloride and sulfate tests. Comparing the behavior of this parameter in the two types of exposure it can be verified that there are two distinct tendencies. On the one hand, the resistivity of the concrete exposed to chlorides tends to decrease throughout the test, probably due to the ionic contamination produced by the penetration of the 


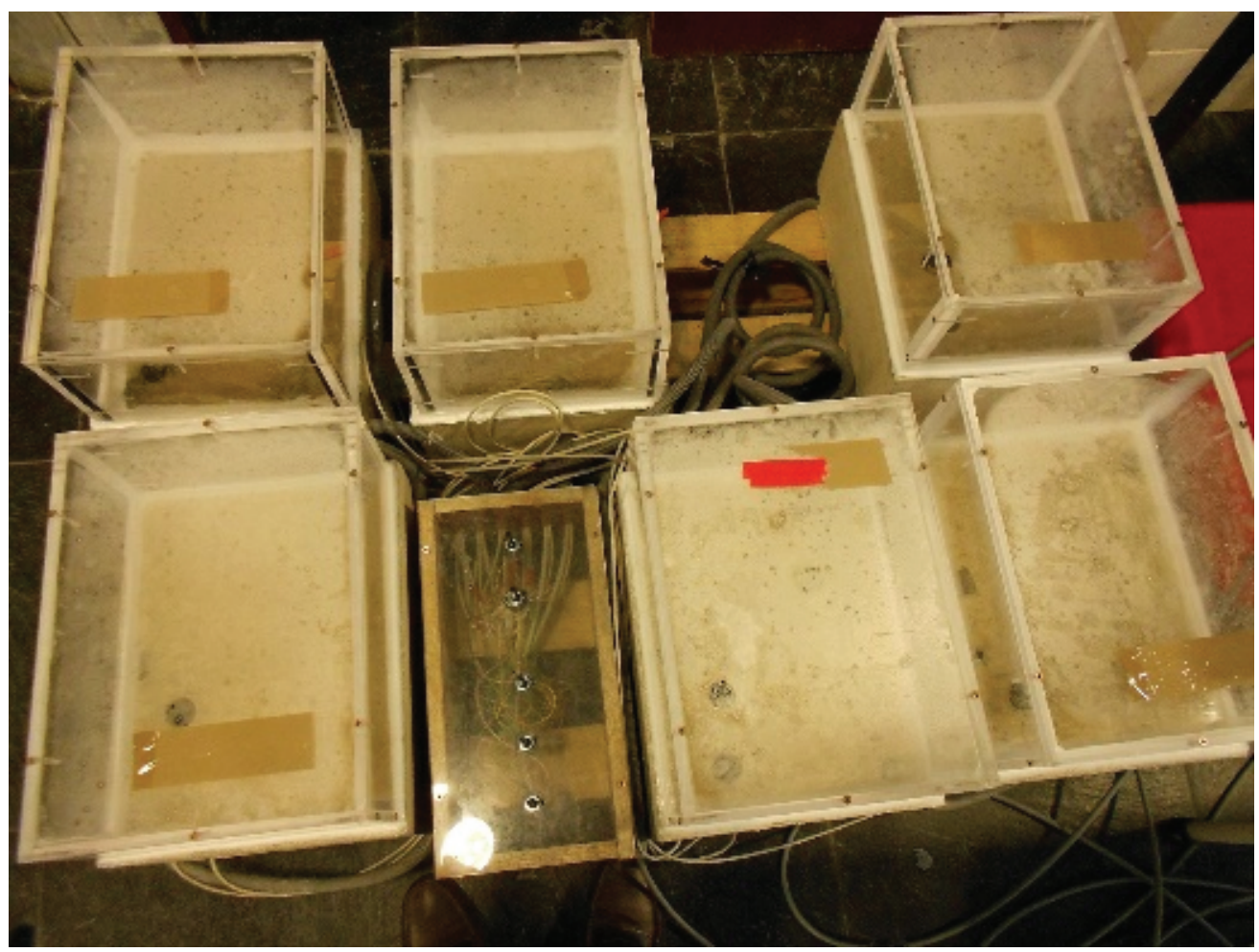

Figure 4: Concrete samples exposed to sulfate attack.

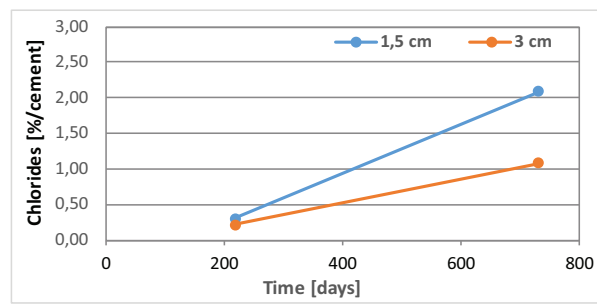

Figure 5: Variation of chlorides concentration by depth over time.

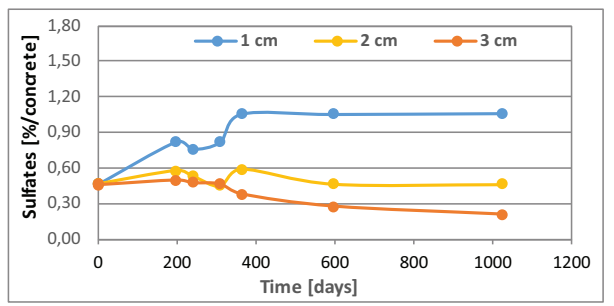

Figure 6: Variation of sulfate concentration by depth over time.

chlorides, which contributes to the increase of the conductivity of the environment. On the other hand, in sulfate tests there is a tendency to increase resistivity, contrary to the expected effect of increased conductivity due to ionic contamination. These data indicate the existence of a mechanism that prevents the progression of sulfate penetration into concrete. 


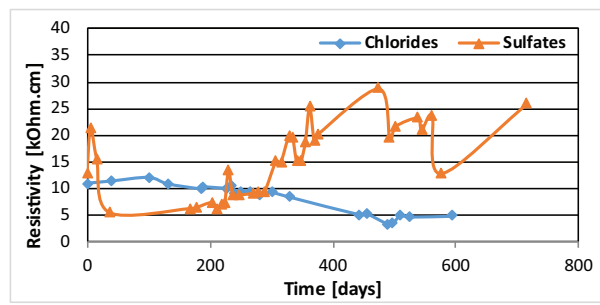

Figure 7: Behavior of the concrete ionic resistivity against the action of chlorides and sulfates.

Analyzing the graph of Fig. 8, which shows the behavior of the corrosion potential of the reinforcement, it can be verified that the behavior of the reinforced concrete exposed to the attack by sulfates is different from the behavior of the concrete subjected to the action of the chlorides. In the sulfate test it can be observed that the corrosion potential of the reinforcement presents a stable behavior at levels considered low risk of corrosion. The graph on chlorides shows a stable behavior up to 400 days, at which point a disturbance occurs which leads to the decrease of potential values to levels of high risk of corrosion.

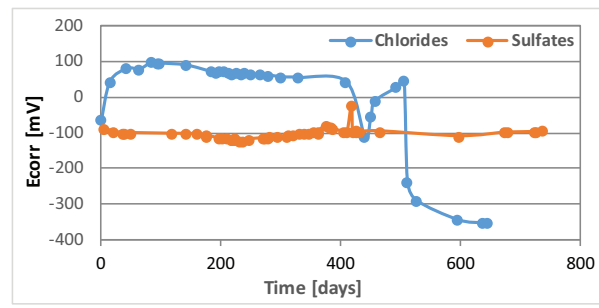

Figure 8: Variation of the corrosion potential of the reinforcement against the action of chlorides and sulfates.

Fig. 9 shows the variation of the linear polarization resistance throughout the tests. The curve for chlorides shows a stable behavior up to 400 days, at which point a disturbance appears that leads to the reduction of this parameter. Regarding the results of the polarization resistance obtained in the sulfate tests, it can be verified that there is a tendency for this parameter to increase over time.

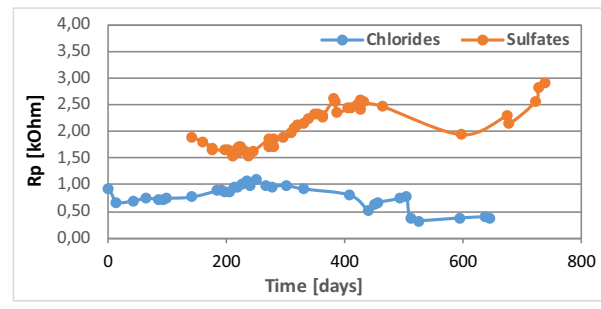

Figure 9: Variation of the polarization resistance of the reinforcement against the action of chlorides and sulfates.

Analyzing the results obtained in the tests with chlorides, it can be verified that for the different variables analyzed a behavior that can be divided into two phases. In a 
first phase the different parameters present stable values associated with a low risk of corrosion of the reinforcement. After 400 days there is a disturbance in the different parameters that leads to changes of the different values to levels that can be considered of high risk of corrosion.

From the results obtained in the tests with sulfates one can verify the existence of a stability or progression of the different parameters showing the existence of a low risk of corrosion of the reinforcement.

These tests indicate the existence of a barrier effect that limits the progression of the attack by sulphates. This effect according to Ikumi et al. is produced by the formation of a layer of magnesium hydroxide [10]. This mechanism associated with the absence of mechanical actions that force the progression of sulfates in depth inhibits the development of corrosion processes of the reinforcement. This phenomenon can be observed through the graphs of corrosion potential and polarization resistance, whose values remain stable throughout the test.

\section{Conclusions}

With the results obtained in these tests it can be concluded that the monitoring systems used:

- make it possible to detect significant changes in the behavior of concrete and steel over time;

- produce relevant information about the behavior of concrete and steel that can contribute to strengthen the maintenance management systems.

Although the results presented by the monitoring systems are consistent with each other and compatible with the concentrations of chlorides and sulphates in the concrete, it is essential to have two or more sources of information that allow data to be crossed to obtain robust conclusions.

\section{References}

[1] F. Pacheco-Torgal and S. Jalali, "Earth construction: Lessons from the past for future eco-efficient construction," Constr. Build. Mater., vol. 29, pp. 512-519, 2012.

[2] P. Pishdad-Bozorgi, X. Gao, C. Eastman, and A. P. Self, "Planning and developing facility management-enabled building information model (FM-enabled BIM)," Autom. Constr., vol. 87, no. December 2017, pp. 22-38, 2018. 
[3] S. Dong, C. Lin, R. Hu, L. Li, and R. Du, "Effective monitoring of corrosion in reinforcing steel in concrete constructions by a multifunctional sensor," Electrochim. Acta, vol. 56, no. 4, pp. 1881-1888, 2011.

[4] E. V. Pereira, R. B. Figueira, M. M. L. Salta, and I. T. E. da Fonseca, "A galvanic sensor for monitoring the corrosion condition of the concrete reinforcing steel: Relationship between the galvanic and the corrosion currents," Sensors, vol. 9, no. 11, pp. 83918398, 2009.

[5] P. Romano, P. S. D. Brito, and L. Rodrigues, "Monitoring of the degradation of concrete structures in environments containing chloride ions," Constr. Build. Mater., vol. 47, pp. 827-832, 2013.

[6] C. Hansson, A. Poursaee, and S. Jaffer, "Corrosion of Reinforcing Bars in Concrete," The Masterbuilder, pp. 106-124, 2012.

[7] H. Karla, C. K. Larsen, and M. R. Geiker, "Relationship between concrete resistivity and corrosion rate - A literature review," 2013.

[8] ASTM International, "ASTM C 876-1991 - Standard Test Method for Corrosion Potentials of Uncoated Reinforcing Steel in Concrete," West Conshohocken, PA, 1999.

[9] ASTM International, "ASTM C 1012-4 - Standard test method for lenght change of hydraulic-cement mortars exposed to a sulfate solution," West Conshohocken, PA, 2004.

[10] T. Ikumi, S. H. P. Cavalaro, I. Segura, A. De Fuente, and A. Aguado, "Simplified methodology to evaluate the external sulfate attack in concrete structures," JMADE, vol. 89, pp. 1147-1160, 2016. 